\title{
Beberapa Pandangan Ibn Ḥajar al-Haytamī Mengenai Pendidikan Kanak-kanak Menerusi Karya Taḥrīr al-Maqāl
}

\author{
Mohd Hasem Almuddin \\ Universiti Malaya, kulambai655@gmail.com \\ Asyraf Isyraqi Jamil \\ Universiti Malaya, isyraqi@um.edu.my \\ Musaiyadah Ahmadun \\ Universiti Malaya, musaiyadah@siswa.um.edu.my
}

\begin{abstract}
Abstrak
Pendidikan kanak-kanak merupakan bahagian yang penting dalam memastikan permulaan dan kelangsungan pendidikan manusia. Ini dibuktikan menerusi khazanah ilmiah Islam silam yang banyak membahaskan perkara ini seperti karya Tahrīr al-Maqāl yang dikarang oleh Ibn Hajar al-Haytamī. Makalah ini meninjau pandangan beliau menerusi karya tersebut tentang perihal pendidikan kanak-kanak. Metode dokumentasi digunakan dalam pengumpulan data, manakala metode analisis kandungan yang merangkumi metode historis, induktif, deduktif dan komparatif digunakan dalam penelitian data. Beberapa pandangan penting diutarakan oleh Ibn Hajar al-Haytamī dalam hal mendidik kanakkanak seperti kefahaman terhadap ilmu dan kaedah pendidikan kanakkanak, keutamaan terhadap pengajaran al-Qur'an bagi kanak-kanak, keperluan memiliki niat yang jelas dalam pengajaran kanak-kanak, kepentingan mengelak syahwat dan fitnah terhadap kanak-kanak, kesediaan melaksana hukuman memukul (darb) berdasarkan sebab dan cara yang benar serta betul terhadap kanak-kanak, keperluan melatih kanak-kanak yang lebih cerdas untuk membantu rakan-rakannya yang lain dan kepentingan merahmati, mengasihi dan mengambil berat halehwal kanak-kanak. Pandangan-pandangan yang diutarakan juga adalah seiring dengan perbahasan para ilmuwan Islam dalam karya-karya mereka berkenaan pendidikan kanak-kanak.
\end{abstract}

Kata kunci: Ibn Ḥajar al-Haytamī, Taḥrīr al-Maqāl, pendidikan kanakkanak, pendidikan Islam

\section{Ibn Hajar al-Haytamī Views of Children's Education Through His Book Taḥrīr al-Maqāl}

\section{Abstract}

Children's education is an important part of ensuring the continuity of education and the beginning of mankind. This is demonstrated in the past Islamic scientific heritage that had been debating regarding 
this issue such as Tahrīr al-Maqal written by Ibn Hajar al-Haytamī. This article reviews the work through his thoughts on the subject of children's education. Documentation methods used in data collection, while the methods of content analysis that includes the historical method, inductive, deductive and comparative were used in research data. Some important views expressed by Ibn Hajar al-Haytamī in terms of educating children as the understanding of the science and methods of education of children, preference for teaching the Koran to children, the need to have a clear intention in teaching children, the importance of avoiding sexual attraction against children, readiness to implement corporal punishment (darb) based on the reasons and the right way towards the child. The needs of children to be trained smarter to help other friends and the importance of mercy, love and care for the affairs of the children. The views expressed are also in line with Muslim scholars in their works regarding children education.

Keywords: Ibn Hajar al-Haytamī, Taḥrīr al-Maqāl, child education, Islamic education

\section{Pendahuluan}

Kanak-kanak sememangnya menjadi tumpuan perbahasan para ilmuwan dahulu dan kini sama ada di Timur mahupun Barat. Perbahasan yang meluas ini tidak terhad hanya kepada bidang akhlak dan pendidikan sahaja, malah melangkaui ke bidang fiqh, sastera, perubatan dan sebagainya. Dalam bidang akhlak dan pendidikan contohnya, ramai ilmuwan Muslim yang terkenal telah membicarakan berkenaan pendidikan kanak-kanak seperti Abu Hāmid al-Ghazzālī (m. 1111) menerusi karya Ayyu-hā al-Walad dan Ibn Qayyim al-Jawziyyah (m. 1350) menerusi karya Tuhfat alMawdūd bi-Aḥkām al-Mawlūd. Jika dilihat dalam bidang fiqh contohnya, al-'Imām al-Shāfi'‘̄ (m. 820) juga menyentuh perihal seorang guru dan anak murid dalam karyanya yang terkenal alUmm dan Ibn Hazm al-Andalusī (m. 1064) pula melalui karyanya al-Muḥallā bi al-'Athār. Jika ditelusuri bidang sastera Arab, tidak ketinggalan juga dibahaskan perihal kanak-kanak seperti Abu Manșūr al-Tha'ālab̄̄ (m. 1038) dalam karyanya al-Tamthīl wa alMuhādarah. Begitu juga dalam bidang perubatan seperti Abu alHasan Aḥmad Muḥammad al-Ṭabarī (m. 976) dalam karyanya alTabīb al-'Arabī yang dianggap sebagai sebuah buku yang tertua juga membahaskan tentang pengubatan kanak-kanak (Tibb al- 
Atfāl). ${ }^{1}$ Selain para ilmuwan Muslim, ahli-ahli falsafah Barat seperti Augustine of Hippo (m. 430) melalui 'De Magistro (The Teacher)', John Locke (m. 1704) melalui 'An Essay to Understand Human Understanding' dan Jean Rousseau (m. 1778) melalui 'Emile: or On Education' juga ada membicarakan tentang halehwal yang sama dalam karya-karya mereka.

Makalah ini merupakan pengenalan terhadap beberapa pandangan seorang tokoh ilmuwan Muslim iaitu Ibn Hajar alHaytamī tentang pendidikan kanak-kanak menerusi karyanya Tahrīir al-Maqāl fì Ādāb wa-Ahkām wa-Fawā'id Yahtāj Ilay-hā Mu'addib al-Atfāl (Perincian Kata Tentang Adab, Hukum dan Faedah Yang Diperlukan oleh Pendidik Kanak-kanak). Makalah ini memberikan gambaran secara umum tentang adab dan hukum serta beberapa perkara yang berkaitan dengan ilmu dan kaedah mendidik kanak-kanak dari sudut pandangan seorang ilmuwan Muslim. Ibn Hajar al-Haytamī telah menyediakan satu dasar pendidikan kanak-kanak yang dibina berasaskan kerangka pemikiran Islam. Dasar tersebut seterusnya berupaya untuk diteliti lebih mendalam ke arah penerapannya dalam sistem pendidikan masa kini.

\section{Biografi Ibn Ḥajar al-Haytamī}

Nama penuh beliau ialah Aḥmad bin Muḥammad Badr al-Dīn bin Muhammad Shams al-Dīn bin 'Alī Nūr al-Dīn bin Hajar alHaytamī. $^{2}$ Al-Haytamī ialah nisbah kepada tempat kelahiran beliau iaitu Mahallah Abu al-Haytam, satu kawasan di barat Mesir. ${ }^{3}$ Terdapat beberapa nisbah lain yang disandarkan kepada beliau iaitu al-Salmunti sebagai nisbah kepada asal keluarganya dari kawasan timur Mesir sebelum berpindah ke Maḥallah Abu alHaytam, ${ }^{4}$ al-Azharī sebagai nisbah kepada tempat beliau menuntut

\footnotetext{
Al-Sarjāni, Rāghib. Qișșah al-'Ulūm al-Haḍ̂arah al-Islamiyyah. (al-Qāhirah: Mu'assasah Iqra', 2009), 64.

2 Al-Sayfĩ. Abu Bakr bin Muḥammad. Nafāis al-Durar F̄̄ Tarjamah Shayikh alIslam Ibn Hajar, no. 26/6, Perpustakan Universiti Malik Soud.

3 Al-Sayfĩ. Nafāis al-Durar; Ibn al-'Imād Shihāb al-Dīn 'Abd al-Ḥayy. Shadharāt al-Dhahab fi 'Akhbār Man Dhahab. (Bayrūt: Dār Ibn Kathīr, 1986), 10:541.

4 Al-Haytamī, Aḥmad bin Muḥammad Ibn Hajar. al-Fatāwā al-Fiqhiyyah alKubrā, (t.tp: Dār al-Fikr, t.t), 1:1; petikan ini diambil dari mukadimah kitab alFatāwā al-Fiqhiyyah al-Kubrā. Mukadimah ini bukannya ditulis oleh Ibn
} 
ilmu iaitu al-Azhar al-Sharīf, ${ }^{5}$ al-Sa 'dī sebagai nisbah kepada Bani Sa'd yang berada di kawasan timur Mesir, ${ }^{6}$ al-Anșari sebagai nisbah kepada Bani Sa'd yang susur galur mereka sampai kepada para sahabat al-Anșār namun dilarang oleh Ibn Hajar al-Haytamī untuk ditulis nisbah ini kerana kewarakannya, ${ }^{7}$ dan al-Shāfi' ${ }^{`} \overline{1}$ sebagai nisbah kepada mazhab beliau iaitu mazhab al-Imām Muhammad bin Idris al- Shāfi'‘ 1.8

Ibn Hajar al-Haytamī dilahirkan pada tahun 909 H/ 1503 M dan beliau dipelihara oleh dua orang ilmuwan setelah kematian bapanya iaitu Shams al-Dīn Abu al-Hamā'il dan Shams al-Dīn alShanāwī. Beliau menuntut ilmu di Mesir dengan beberapa orang ilmuwan seperti al-Qādi Zakariyyā al-Anșāri, al-'Allāmah alAmīn al-Ghumarī, Shihab al-Dīn al-Ramlī al-Shāfi ‘ī dan Shihāb al-Dīn bin al-Najjār al-Hanbalī. ${ }^{9}$

Ibn Hajar al-Haytamī menetap di Mesir dan mengajar di sana sehingga tahun $940 \mathrm{H} / 1533 \mathrm{M}$ apabila beliau kemudiannya berpindah ke Makkah dan mula mengajar di situ. Antara peribadi yang pernah menjadi murid beliau ialah al-Shaykh Ahmad bin Qāsim al-'Abbadī, al-Shaykh al-Burhān bin al-Ahdab, al-Shaykh 'Abd al-Raḥmān bin 'Umar al-'Amūdi dan al-Shaykh Muḥammad bin Aḥmad al-Fāqihi. ${ }^{10}$

Karya-karya yang pernah dihasilkan oleh Ibn Hajar alHaytamī merangkumi pelbagai bidang seperti hadith, aqidah, fiqh, akhlak, bahasa dan sastera Arab, falak, sirah nabawiyyah, sejarah Islam dan biografi ilmuwan. Jumlah hasil tulisan beliau mencapai 117 buah karya. ${ }^{11}$ Antara karya yang terkenal ialah al-Fatāwā al-

Hajar al-Haytamī tetapi oleh seorang muridnya iaitu Muhammad bin Ahmad bin 'Ali al-Fākihi lahir pada $923 \mathrm{H}$ dan wafat pada $982 \mathrm{H}$. Lihat Al-'Aydarūs, 'Abd al-Qādir bin Shaykh. al-Nūr al-Sāfir 'an 'Akhbār al-Qarn al-'Āṣir. (Bayrūt: Dār Șādir, 2001), 464; Ibn al-'Imād, Shadharāt al-Dhahab, 10:582.

5 Lamyā' Ahmad Abdullah Shāfi'î, "Ibn Hajar al-Makki wa Juhūduhu fi alKitābah al-Tārīkhiyyah”, (tesis kedoktoran, Universiti Umm Al-Qurā, 1996), 17; Ibn al-'Imād, Shadharāt al-Dhahab, 10:541.

6 Al-'Aydarūs, al-Nūr al-Sāfir, 395; Al-Sayfi. Nafāis al-Durar.

Al-Haytamī, al-Fatāwā al-Fiqhiyyah al-Kubrā , mukadimah.

8 'Abd al-Mu'iz 'Abd al-Ḥamīd. Ibn Hajar al-Haytamī, (al-Qāhirah: t.p, 1981), 27.

9 Muhammad bin 'Abd al-'Azīz, Ārā' Ibn Hajar al-Haytam̄̄ al-I'tiqādiyah, (Riyāḍ: Maktabah Dār al-Manhaj, 2006) 35. Al-Sayfī, Nafāis al-Durar.

10 Muhammad bin 'Abd al-'Azīz, Ārā' Ibn Hajar, 38.

11 Lamyā', Ibn Hajar al-Makkī wa Juhūduhu, mukadimah. 
Fiqhiyyah al-Kubrā, al-Fath al-Mubīn bi Sharh al-Arba'in, alFatāwā al-Hadīthiyyah.

Ibn Hajar al-Haytamī meninggal dunia pada tahun $974 \mathrm{H} /$ $1566 \mathrm{M}^{12}$ di Makkah dan dikebumikan di Perkuburan al-Ma'la di kawasan Turbah al-Tabariyyin.

\section{Kandungan Tahrīr Al-Maqāl}

Ibn Hajar al-Haytamī menjelaskan di bahagian pendahuluan Tahrìr al-Maqāl bahawa beliau telah ditanya dengan beberapa soalan oleh beberapa orang pendidik kanak-kanak pada tahun 957 $\mathrm{H} / 1550 \mathrm{M} \cdot{ }^{13}$ Setelah melihat kepada soalan-soalan dan jawapanjawapan yang disediakannya, maka beliau berpandangan bahawa eloklah jawapan-jawapan tersebut dikarang dalam bentuk sebuah buku yang mengandungi pembahagian-pembahagiannya.

Maka lahirlah sebuah buku yang diberi tajuk Tahrīr al-Maqāl fi Ādāb wa-Ahkē̄m wa-Fawā'id Yahtāj Ilay-hā Mu'addib al-Atfāl (Perincian Kata Tentang Adab, Hukum dan Faedah Yang Diperlukan oleh Pendidik Kanak-kanak). Buku tersebut mengandungi satu muqaddimah (pendahuluan), tujuh maqāsid (tujuan) dan satu khätimah (penutup) yang boleh diperincikan seperti berikut:

○ Muqaddimah (Pendahuluan)

- Maqsad Awwal (Tujuan Pertama): Berkenaan Hadis-hadis Yang Menjadi Dalil Kemuliaan Ahli al-Qur'an

- Maqsad Thāni (Tujuan Kedua): Berkenaan Hadis-hadis Yang Berkaitan Kelebihan Pengajar dan Pelajar al-Qur'an

- Maqsad Thālith (Tujuan Ketiga): Berkenaan Keharusan Mengambil Upah Dalam Pengajaran al-Qur'an, Ruqyah Dengannya dan Sebagainya

- Maqsad Rābí (Tujuan Keempat): Berkenaan Dalil Yang Melarang Mengambil Upah Dalam Pengajaran al-Qur'an

12 Al-Sayfi. Nafāis al-Durar, 7; al-'Aydarūsi, al-Nūr al-Sāfir, 390; Najm al-Dīn al-Ghazzi. al-Kawākib al-Sā'irah bi 'A'yāni al-Mi'ah al-'Āshirah,( Bayrūt: Dār al-Kutub al-'Ilmiah, 1997), 3:102.

13 Al-Haytamī, Ahmad bin Muhammad Ibn Hajar. Tahrir al-Maqāl fì Ādāb wa Aḥkām wa Fawā'id Yaḥtāju Ilayha Mu'addib al-Atfāl, sunt. Muhammad Nur al-Din Marbu Banjar al-Makkī, (al-Qāhirah: Majlis al-Banjari li al-Tafaqquh fī al-Dīn, 1997), 23. 
- Maqsad Khāmis (Tujuan Kelima): Perbezaan Dalam Kalangan Ilmuwan Tentang Hal Tersebut (Mengambil Upah Dalam Pengajaran al-Qur'an)

- Maqsad Sādis (Tujuan Keenam): Peringatan Berkenaan Memandang Kepada al-Marad (Anak Kecil Yang Berwajah Lembut Sehingga Boleh Menimbulkan Syahwat atau Fitnah)

- Maqsad Sābi (Tujuan Ketujuh): Berkenaan Soalan-soalan dan Jawapan-jawapan Yang Menjadi Sebab Pengarangan Buku Ini

o Khätimah (Penutup).

\section{Ibn Hajar al-Haytami dan Pendidikan Kanak-kanak}

Dalam menjawab persoalan-persoalan yang dilontarkan kepada Ibn Hajar al-Haytamī, dapat dilihat bahawa beliau telah menjelaskan beberapa pandangan yang berkaitan dengan pendidikan kanak-kanak menerusi buku tersebut. Sebagai suatu pengenalan, maka disenaraikan pandangan-pandangan yang dimaksudkan itu yang perlu diberi perhatian oleh para pendidik khususnya pendidik kanak-kanak. Terdapat tujuh pandangan yang boleh dirumuskan daripada keseluruhan penulisan Ibn Hajar alHaytamī dalam Tahrīir al-Maqāl. Mungkin terdapat pandanganpandangan lain yang boleh difahami daripada penulisan buku tersebut, namun kertas ini hanya menyenaraikan pengenalan tujuh pandangan yang dapat difahami secara jelas dalam penulisan Ibn Hajar al-Haytamī itu.

\section{1) Memahami ilmu dan kaedah pendidikan kanak-kanak}

Walaupun ia tidak dinyatakan secara langsung dalam Tahrīr alMaqāl, namun ia dapat diperhatikan dengan jelas dalam pendahuluan buku tersebut. Kata Ibn Hajar al-Haytamī:

Faqad warada 'alayya min ba 'ḍi șulaḥ̄' mu'addibī al-atfāl thāni jumāda al-ulā sanata sab 'a wa-khamsīn wa-tis 'imi'ah as'ilah mufahimah (Pada 2 Jumada al-Ula tahun 957, telah sampai kepadaku dari sebahagian pakar mu'addib [pendidik] kanak-kanak beberapa soalan yang sukar untuk dijawab, dan [menjadi] kemestian bagiku untuk menyemak jawapannya). ${ }^{14}$

Keseriusan Ibn Hajar al-Haytamī dalam menekankan kepentingan memahami ilmu dan kaedah pendidikan kanak-kanak ini lebih jelas kelihatan apabila beliau mengarang sebuah lagi

14 Al-Haytamī, Taḥrir al-Maqāl, 23. 
karya dalam bidang yang sama iaitu Adāb al-Mu'allim wa'lMuta'allim selepas enam belas tahun iaitu pada tahun $973 \mathrm{H} / 1565$ M sebagai kesinambungan kepada Tahrīr al-Maqāl. Ketika alSayfi ${ }^{15}$ menisbahkan kitab Tahrīr al-Maqāl kepada Ibn Hajar alHaytamī, beliau menyatakan tentang wujudnya "mu'allafan $\mathrm{ka}$ ' ldhayl 'alay-hi awsa' min-hu (sebuah penulisan seperti ekor [penyambung] kepadanya yang lebih luas [perbahasan] darinya) ${ }^{16}$ iaitu merujuk kepada karya Adāb al-Mu'allim wa'l-Muta 'allim.

Para ilmuwan Islam sememangnya amat mementingkan ilmu dan kaedah pendidikan kanak-kanak ini. Hal ini dibuktikan dengan kewujudan banyak karya yang membahaskan perkara ini dan dinisbahkan kepada para ilmuwan Islam. Sebagai contoh ialah alImam Abu Hanifah (m. $150 \mathrm{H}$ ) dengan karya al-'Álim wa'alMuta'allim, al-Jāhiz (m. $163 \mathrm{H})$ dengan karya al-Mu'allimin, Ibn Sahnūn (m. $256 \mathrm{H})$ dengan karya Ādab al-Mu'allimīn, Abu Bakr al-Balkhi (m. $280 \mathrm{H})$ dengan karya al-'Ālim wa'al-Muta'allim, alQābisī (m. $403 \mathrm{H})$ dengan karya al-Risālah al-Mufaș̣alah liAhwwāl al-Mu 'allimin wa'l-Muta'allimin, Ibn Miskawayh (m. 421 H) dengan karya Tahdhīb al-Akhlāq wa-Tațhìr al-A 'rāq, Ibn Sīnā (m. $428 \mathrm{H})$ dengan karya al-Siyāsah, al-Khațīb al-Baghdādī (m. $462 \mathrm{H})$ dengan karya al-Faqīh wa'al-Mutafaqqih, Ibn 'Abd alBarr (m. $463 \mathrm{H})$ dengan karya Jāmi' Bayān al-'Ilm wa-Fadli-hi wa-mā Yanbaghi fi Riwāyati-hi wa-Hamli-hi, al-Ghazzālī (m. 505 H) dengan karya Ayyu-hā al-Walad, al-Sam'āni (m. $562 \mathrm{H}$ ) dengan karya Adab al-Imla' wa'al-Istimlā', al-Nawawī (m. $676 \mathrm{H})$ dengan karya Ādāb al-'Ilm wa'al-'Ālim wa'al-Muta'allim, Ibn Qayyim al-Jawziyyah (m. $751 \mathrm{H})$ dengan karya Tuhfat al-Mawdūd bi-Ahkām al-Mawlüd, dan ramai lagi.

Secara umumnya, perbahasan yang diketengahkan dalam Tahrīr al-Maqāl lebih menjurus kepada pelajar yang merupakan anak yatim. Ini sekaligus menunjukkan kepada kategori umur belajar di sekolah (maktab). Pada masa itu masyarakat sekeliling

\footnotetext{
15 Abu Bakr bin Muhammad bin 'Abdullah al-Sayfi hidup sebelum $973 \mathrm{H}$ dan tidak diketahui tarikh kewafatannya. Beliau merupakan anak murid Ibn Hajar al-Haytamī yang menulis kitab Nafäis al-Durar F̄̄ Tarjamah Shaikh al-Islām Ibn Hajar. Lihat Lamyā', Ibn Hajar al-Makki wa Juhūduhu, 78.

${ }^{16}$ Lamyā', Ibn Hajar al-Makki wa Juhūduhu, 292.
} 
cenderung kepada keterbukaan kategori umur belajar bagi anakanak mereka. ${ }^{17}$

Jika ditelusuri latar belakang Ibn Hajar al-Haytamī, didapati sedikit sebanyak dapat diketahui sebab beliau mementingkan halhal seumpama ini. Ibn Hajar al-Haytamī sendiri ada menyatakan secara jelas dalam muqaddimah al-Fatāwā al-Fiqhiyyah al-Kubrā bahawa beliau menderita daripada gangguan sebahagian para pelajar yang hadir bersamanya ketika beliau menuntut ilmu di alAzhar. ${ }^{18}$ Justeru, amatlah penting bagi seorang pendidik untuk memahami ilmu dan kaedah mendidik agar dengan yang demikian dapat mengelak daripada masalah gangguan yang berlaku dalam proses pengajaran dan pembelajaran. Hal ini juga menunjukkan peranan penting yang dimainkan oleh seorang pendidik dengan tidak hanya tertumpu kepada penyampaian ilmu semata-mata, khususnya bagi para pendidik kanak-kanak.

\section{2) Mengawali dengan mengajar al-Qur'an bagi kanak-kanak}

Dalam dua maqsad yang terawal dalam Tahrīr al-Maqāl, Ibn Hajar al-Haytamī menyenaraikan hadis-hadis berkaitan dengan ahli al-Qur'an dan kelebihan mereka, dan kelebihan pengajaran dan pembelajaran al-Qur'an serta mereka yang terlibat dengannya. ${ }^{19}$ Hal ini mengisyaratkan kepada keperluan untuk memulakan pengajaran dan pembelajaran ilmu al-Qur'an bagi kanak-kanak Muslim khususnya sebelum mereka mendalami cabang-cabang ilmu yang lain agar mereka memiliki asas yang kukuh, bahkan menjadi panduan kepada mereka dalam mendepani kehidupan. Perkara ini sebenarnya merupakan tradisi ilmuwan Muslim silam khususnya ilmuwan yang berbicara tentang pendidikan seperti Ibn Sahnūn. ${ }^{20}$ Ini boleh dilihat dalam karya beliau yang bertajuk Adāb al-Mu'allimīn yang memulakan karyanya itu dengan bab yang bertajuk Mā Jā'a fi Ta'lìm alQur'ān (Apa Yang Berkaitan Dengan Pengajaran al-Qur'an).

17 Sulaimān Hussain al-Mazīn, "Qirā'ah Tarbawiyyah fi Adab al-Aṭāal”, Majallat al-Jāmi 'ah al-Islāmiyyah, 14, 1, (jan 2006), 243.

18 Al-Haytamī, al-Fatāwā al-Fiqhiyyah al-Kubrā. 1:4.

19 Al-Haytamī, Tahrir al-Maqāl, $25-54$.

20 Ahmad Ubaedi Fathuddin, "Pemikiran Ibn Shahnun Tentang Belajar Mengajar al-Qur'an”, Forum Tarbiyah, 8, 2, ( 2010), 193 - 202. 
Dalam memperlihatkan kepentingan ini, beliau telah menyenaraikan hadis-hadis yang menyebut tentang kedudukan ahli al-Qur'an sebagai manusia yang mendapat perhatian khusus dari Tuhan, malah merupakan semulia-mulia umat Nabi Muhammad s.a.w. Antaranya ialah hadis yang diriwayatkan oleh al-Imam Ahmad yang bermaksud: ((Sesungguhnya Allah SWT mempunyai ahli-ahli-Nya (ahalina) daripada kalangan manusia, mereka itu ahli Allah dan pilihan-Nya)). ${ }^{21}$ Begitu juga dengan hadis-hadis yang menyebut tentang kedudukan pengajar dan pelajar al-Qur'an sebagai manusia yang terbaik, malah beroleh ganjaran yang istimewa di Akhirat kelak. Antaranya ialah hadis yang diriwayatkan oleh al-Imām Ahmad juga yang bermaksud: ((Sebaik-baik kalian ialah orang yang mempelajari al-Qur'an dan mengajarkannya)). ${ }^{22}$

\section{3) Memiliki niat yang jelas dalam pengajaran kanak-kanak}

Perkara ini diberikan perhatian oleh Ibn Hajar al-Haytamī menerusi perbahasannya dalam tiga maqsad dan beberapa bahagian daripada maqsad yang ketujuh iaitu ketika membincangkan tentang hukum mengambil upah ketika mengajar al-Qur'an. Beliau cenderung kepada hukum keharusan mengambil upah daripada pengajaran al-Qur'an. Berbeza dengan al-Imām Abu Ḥanīfah dan Isḥāq bin Rahawayh yang berpandangan bahawa

${ }^{21}$ Hadith riwayat Ibn Mājah, man ta'allam al-Qurān wa 'allamahu, no. Hadith 215. Lihat Abu 'Abdullah Muhammad bin Yazīd al-Qazwīn̄̄, Sunan Ibn Mājah, ed. Muhammad Fuād 'Abd al-Bāqīi (t.tp: Dār 'Ihyā' al-Kutub al'Arabiyyah, t.t), 1:78.

${ }^{22}$ Hadith riwayat Ahmad, Musnad al-'Asharah al-Mubashirīn bi al-Jannah, no. Hadith 402. Al-Bukhāri, Bab Faḍāil al-Qurān, no. Hadith 5027. Abu Daud, bab Solat, no. Hadith 1452. al-Tirmidhi, kitab Faḍāil al-Qurān, no. Hadith 2907. dan Ibn Mājah, bāb fạ̣l man ta'allam al-Qurān wa 'allamahu, no. Hadith 211. Lihat Abu 'Abdullah Ahmad bin Hanbal, Musnad al-'Imām Ahmmad, ed. Aḥmad Muhammad Shākir (al-Qāhirah: Dār al-Ḥadīth, 1995), 1:336; Muḥammad bin Ismā'il, Șaḥịh al-Bukhārī, ed. Muḥammad Zuhayr bin Nāṣir al-Nāṣir (t.tp., Dār țauq al-Najāh, 2001), 6:192; Sulaimān al-'Ash'ash alSijistānī, Sunan Abi Daud, (t.tp: Dār al-Risālah al-'Ilmiyyah, 2009), 2:582; Muhammad bin 'īsā al-Tirmidhī, al-Jāmi'al-Kabīr, ed. Bashār 'Iwād Ma'rūf (Bayrūt: Dār al-Gharb al-Islāmī, 1998) 5:23; dan Abu 'Abdullah Muḥammad bin Yazīd al-Qazwīn̄i, Sunan Ibn Mājah, ed. Muḥammad Fuād 'Abd al-Bāqī (t.tp: Dār 'Ihyā'’ al-Kutub al-'Arabiyyah, t.t), 1:76 
tidak boleh mengambil upah dan balasan daripada pengajaran alQur'an. ${ }^{23}$

Ibn Ḥajar al-Haytamī berkata:

Faal-haqq al-ladhi shahidat bi-hi al-qawā id al-ușuliyyah wa al-hadìthiyyah jawāz akhdha al-'ujrah 'alā ta 'lìm al-Qur'ān bi-'aqd sahīh (Maka [pendapat] yang betul yang disaksikan oleh kaedah usul dan hadith [ialah] dibolehkan pengambilan upah ke atas pengajaran al-Qur'an yang berasaskan perjanjian yang sebaiknya)."

Dalam memperlihatkan lagi kepentingan perkara ini, maqsad ketiga, keempat dan kelima kelihatan sengaja ditonjolkan oleh beliau sebelum beliau meneruskan perbincangan perkara yang lebih mendalam yang banyak dibincangkan dalam maqsad keenam dan ketujuh. Ibn Hajar al-Haytamī mengatakan:

Lam arā man jama'a hädhihi al-'ahādīth fi hādhayn almaqșadayn wa-istawfā-humā kamā fa'altu fa'tani bi-hifzihimā (Aku belum pernah melihat seorang pun yang mengumpulkan hadis-hadis dalam dua maqsad ini dan mengumpulkannya dengan sempurna seperti mana yang telah aku lakukan, maka hendaklah engkau memberi perhatian [yang serius] untuk menghafal [menjaga] kedua-duanya [maqsad]). ${ }^{25}$

\section{4) Mengelak syahwat dan fitnah terhadap kanak-kanak}

Pada maqsad yang keenam dalam Taḩrīr al-Maqāl, Ibn Ḥajar alHaytamī memberi peringatan kepada para pendidik agar tidak terjerumus ke dalam lembah syahwat atau fitnah terhadap kanak$\mathrm{kanak}^{26}$ ataupun yang dikenali pada masa kini dengan perbuatan 'Pedofilia'. Menurut Pertubuhan Kesihatan Sedunia (WHO), Pedofilia adalah sejenis gangguan psikologi di mana seseorang individu tertarik secara seksual kepada kanak-kanak yang belum mencapai umur baligh. ${ }^{27}$ Justeru, menurut Ibn Hajar al-Haytamī,

23 Al-Haytamī, Taḥrir al-Maqāl, 79. Lihat Muḥammad Shams al-Ḥaq Ābādī, 'Aun al-Ma'būd, (t.tp: Dār al-Kutub al- 'Ilmiyyah, 1995) 9:204.

24 Al-Haytamī, Tahrir al-Maqāl, 83.

25 Ibid., 71.

26 Ibid., 89.

27 International Statistic Classification of Diseases and Related Health Problems: The ICD 10 Classification of Mental and Behavioural Disorders, World Health Organization. Bahagian F65.4, h.171. 
terdapat kanak-kanak yang sebahagiannya memiliki wajah yang lembut dan menarik perhatian melebihi seorang wanita, dan kanak-kanak ini lebih dikenali dengan istilah al-amrād. ${ }^{28}$

Ibn Hajar al-Haytamī menegaskan perkara ini dengan menyatakan tentang keharusan guru memandang wajah al-amrād tetapi perlu menjaga pandangannya seboleh mungkin kerana bimbang terhadap syahwat dan fitnah. ${ }^{29}$ Menurut beliau lagi, secara hukum asalnya, adalah haram untuk seseorang melihat kepada wajah perempuan ajnabi walaupun wajahnya itu bersifat tua atau hodoh. Justeru, dalam hal yang berkaitan dengan alamrād, adalah wajar bagi seseorang untuk berhati-hati walaupun pandangannya itu bebas daripada syahwat dan fitnah kerana mengambil langkah berjaga-jaga supaya tidak membawa kepada perkara yang tidak dingini. ${ }^{30}$

Sebagai contoh, beliau menyenaraikan hadis-hadis yang mengisyaratkan bahawa pandangan mata manusia boleh dianggap sebagai salah satu daripada bentuk perzinaan, malah sebagai salah satu daripada panahan Iblis jika pandangan mata tersebut mengundang rasa syahwat atau membawa kepada fitnah. Antaranya ialah hadis yang diriwayatkan oleh al-Hākim yang bermaksud: ((Pandangan itu merupakan satu anak panah daripada anak-anak panah Iblis, barang siapa yang meninggalkannya kerana takutkan Allah, maka Allah akan tukarkannya dengan Iman yang dapat dirasai kemanisannya dalam hati)). ${ }^{31}$ Begitu juga dengan hadis yang diriwayatkan oleh al-Ṭabarān̄̄ yang bermaksud: ((Tiga mata yang tidak akan melihat api neraka; 1) Mata yang berjaga pada jalan Allah, 2) Mata yang menangis kerana takutkan Allah, dan 3) Mata yang ditahan daripada melihat perkara-perkara yang diharamkan oleh Allah)). ${ }^{32}$

${ }^{28}$ Menurut Ibn Manẓūr dalam al-Lisān "murd (al-amrād) : pemuda yang baru tumbuh janggut dan misainya. Lihat Ibn Manz̄ūr Muḥammad bin Mukram, Lisān al- 'Arab, (Bayrūt: Dār șadir, 1993) 3:401

29 Al-Haytamī, Tahrir al-Maqāl, 97.

${ }^{30}$ Ibid,. 96.

31 Hadith riwayat al-Ḥākim, kitāb al-Raqāq, Bab uzhud fi al-Dunia yuhibbukallah, no. Hadith 7875. Lihat Abu 'Abdullah Muhammad Bin 'Abdullah al-Hākim, al-Mustadrak 'alā al-Ṣohihain, (Bayrūt: Dār al-Kutub al'Ilmiyah, 1990) 4:349.

32 Hadith riwayat al-Ṭabarāni, bab al-Mīm, no.hadith 1003. Lihat Sulaimān bin Ahmmad al-Ṭabarāni, al-Mu ‘jam al-Kabīr, (al-Qāhirah: Maktabah Ibn Taymiyah, 1994) 19:416. 
5) Melaksanakan hukuman memukul (darb) berdasarkan sebab dan cara yang benar serta betul terhadap kanak-kanak Pada maqsad yang ketujuh, ${ }^{33}$ Ibn Hajar al-Haytamī memberikan jawapan terhadap beberapa persoalan yang berkaitan dengan perlaksanaan hukuman memukul (darb) terhadap kanak-kanak. hukuman memukul (darb) secara fizikal seperti merotan merupakan perbahasan yang masyhur dalam kalangan ilmuwan Muslim silam. Pendapat imam mazhab yang empat mengharuskannya dengan pelbagai syarat kerana mereka menyatakannya sebagai salah satu daripada hukuman ta'zīr (denda). ${ }^{34}$ Justeru, Ibn Ḥajar al-Haytamī turut membahaskan perkara yang sama, malah perbahasan mengenai hukuman memukul (darb) secara fizikal ini merupakan perbahasan yang terpanjang dalam Tahrīr al-Maqāl. Sudut pandang jawapan beliau tersebut mungkin berasaskan kepada pengalaman hidup beliau sendiri sebagaimana yang beliau nyatakan:

Qāṣaytu ayḍdan min al-īdha' ' $\min$ ba'ḍi ahl al-durūs allati kunnā nahḍru-hā (Aku juga telah menderita daripada gangguan sebahagian pelajar yang hadir bersama kami dalam pembelajaran). ${ }^{35}$

Beliau membicarakan secara khusus berkenaan hukuman memukul (darb) secara fizikal tersebut yang boleh dirumuskan seperti berikut:

a. Hukuman haruslah mendapat keizinan daripada ayah, ibu atau penjaga kanak-kanak tersebut. ${ }^{36}$

b. Tujuan melaksanakan hukuman ialah untuk memperbaiki keadaan mereka seperti membangkitkan semangat untuk belajar dan sebagainya. Hal ini bergantung kepada pertimbangan pendidik untuk melihat kewajaran hukuman tersebut. Dilarang sama sekali pendidik melaksanakan hukuman itu dengan tujuan untuk menghalau pelajar dari sekolah, menyakitinya dan sebagainya. $^{37}$

33 Al-Haytamī, Tahrir al-Maqāl, 99 - 154.

${ }^{34}$ Latīfah Hussin al-Kandari. Ta'dīb al-Ṭifl bi al-Lutf lā bi al- 'Unf. (al-Kuwait: wizārah al-Tarbiyah, 2011), 78.

35 Al-Haytamī, al-Fatāwā al-Kubrā al-Fiqhiyah, 1:4.

36 Al-Haytamī, Tahrir al-Maqāl, 116.

37 Al-Haytamī, Tahrir al-Maqāl, 119. 
c. Hukuman dilaksanakan terhadap kesalahan yang datang daripada pelajar dengan syarat terdapat kesahan mengenai kesalahan itu melalui penyaksian sendiri oleh guru ataupun laporan daripada peribadi yang boleh dipercayai. ${ }^{38}$

d. Hukuman boleh dilaksanakan ke atas pelajar yang menyakiti guru itu sendiri. ${ }^{39}$

e. Hukuman perlu dilaksanakan secara setimpal dengan kesalahan yang dilakukan dan bukannya untuk mendera dan mencederakan. ${ }^{40}$

f. Tidak boleh melaksanakan hukuman di bahagian muka atau mana-mana bahagian yang boleh membunuh seperti kemaluan, bawah telinga atau kawasan tengkuk. ${ }^{41}$

g. Hukuman yang dibuat beberapa kali perlu dibuat di bahagian anggota badan yang berasingan, tidak di satu tempat sahaja. ${ }^{42}$

h. Jika hukuman dibuat melebihi sekali, maka hukuman yang kedua harus mengambil kira tempoh masa yang boleh mengurangkan kesakitan daripada hukuman yang pertama. ${ }^{43}$

i. Ketika melakukan hukuman khususnya memukul, hanya bahagian lengan tangan bawah (pergelangan tangan hingga ke siku) sahaja yang boleh diangkat, manakala bahagian lengan tangan atas (siku hingga ke bahu) tidak boleh diangkat, apatah lagi jika ia boleh menampakkan kulit bawah bahagian lengan tangan atas. Jika kedua-dua bahagian lengan tangan bawah dan atas turut diangkat, ia boleh memberikan kekuatan tambahan kepada pukulan yang dilakukan. ${ }^{44}$

j. Bahagian lengan tangan bawah (pergelangan tangan hingga ke siku) perlulah diangkat agar dapat memberikan rasa pukulan kepada mereka yang dihukum. Jika tidak diangkat, maka pukulan tidak akan meninggalkan apa-apa rasa sakit kepada mereka yang dihukum. ${ }^{45}$

\footnotetext{
38 Ibid., 119.

39 Ibid., 121.

Ibid.

41 Ibid., 123.

${ }^{42}$ Ibid.

43 Ibid..

44 Ibid., 124.

45 Ibid.
} 
k. Alat yang digunakan untuk memukul haruslah terdiri daripada objek bersaiz sederhana, tidak terlalu besar atau terlalu kecil. ${ }^{46}$

1. Alat yang digunakan untuk memukul haruslah terdiri daripada sesuatu yang bersifat seperti rotan dan sebagainya. ${ }^{47}$

m. Alat yang digunakan untuk memukul haruslah bersifat pertengahan antara basah dan kering. Juga tidak terlalu keras dan tidak terlalu lembut. ${ }^{48}$

n. Hukuman boleh dilaksanakan lebih daripada tiga kali berdasarkan kepada tujuan hukuman dan keadaan yang tidak membawa mudarat kepada mereka yang dihukum. ${ }^{49}$

\section{6) Melatih kanak-kanak yang lebih cerdas untuk membantu rakan-rakannya yang lain}

Ibn Hajar al-Haytamī membicarakan dalam maqsad yang ketujuh berkenaan keharusan meminta kanak-kanak yang lebih cerdas untuk mengajar rakan-rakannya yang lain. ${ }^{50}$ Ibn Hajar al-Haytamī menyatakan bahawa hal itu diharuskan kerana beliau melihat ia bukannya bertujuan untuk mengurangkan beban tugas yang diamanahkan kepada guru, tetapi lebih kepada membantu kanakkanak yang membantu rakan-rakannya yang lain itu untuk mengekalkan hafazan atau menambah latihan, malah memudahkan mereka dalam pengajian yang seterusnya. ${ }^{51}$

\section{7) Merahmati, mengasihi dan mengambil berat hal-ehwal kanak-kanak}

Pada penutup (khatimah) Taḥrīr al-Maqāl, Ibn Hajar al-Haytamī menyenaraikan hadis-hadis yang menggalakkan para pendidik untuk merahmati dan mengasihi pelajar-pelajar mereka khususnya kanak-kanak, malah mengambil berat terhadap hal-ehwal diri mereka. ${ }^{52}$ Antaranya ialah hadis yang diriwayatkan oleh alBukhari yang bermaksud: (Barangsiapa yang tidak menyayangi,

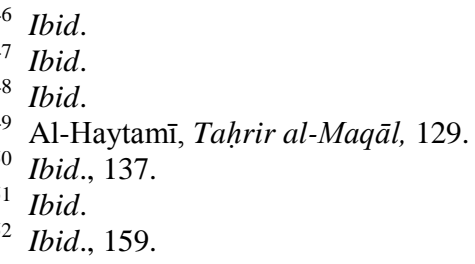


maka dia tidak akan disayangi). ${ }^{53}$ Selain itu, Ibn Hajar al-Haytamī juga menyenaraikan hadis-hadis yang menyatakan tentang rahmat bagi manusia yang merahmati manusia yang lain dan penafian Nabi Muhammad s.a.w sebagai umat Baginda terhadap manusia yang tidak merahmati kanak-kanak yang kecil..$^{54}$ Justeru, seorang pendidik khususnya pendidik kanak-kanak haruslah bersifat merahmati dan mengasihi para pelajar mereka di samping mengambil berat hal-ehwal mereka agar kanak-kanak tersebut lebih bersedia untuk menerima didikan, dalam masa yang sama tidak mengabaikan hukuman terhadap mereka sekiranya mereka melakukan kesalahan dan kesilapan yang sewajarnya.

\section{Penutup}

Melalui perbincangan dalam Taḥrīr al-Maqāl, Ibn Ḥajar alHaytamī dalam hal pendidikan kanak-kanak dilihat amat mementingkan peribadi guru sebagai sosok yang memberi kesan yang besar terhadap kehidupan kanak-kanak itu sendiri. Selain sebagai seorang penyampai ilmu, Ibn Hajar al-Haytamī juga memperlihatkan guru sebagai seorang pentadbir setiap pelajarnya dari segenap sudut merangkumi kemahiran, akhlak, harta dan sebagainya.

Pendidikan kanak-kanak mendapat perhatian para ilmuwan Islam untuk dibicarakan dalam karya-karya mereka berdasarkan keperluan dan kepentingannya dalam pembangunan peribadi kanak-kanak. Ilmu dan kemahiran pendidikan awal kanak-kanak yang salah berpeluang menjadikan mereka tersasar daripada menjadi seorang manusia yang baik. Ibn Hajar al-Haytamī telah menyediakan satu dasar pendidikan kanak-kanak yang dibina berasaskan kerangka pemikiran Islam. Dasar tersebut seterusnya

53 Hadith riwayat Bukhari, Kitab al-Adab, Bab raḥmah al-Walad wa taqbīluhu wa mu'ānaqatuhu, no. hadith 5997 dan Muslim, Kitab al-Faḍāil, bāb Raḥmatihi șallallāh 'alayhi wa sallam al-ṣibyān wa al-'iyāl wa tawāḍu'ihi wa faụl zālik, no. hadith 2318. Lihat Muḥammad bin Ismā'il, Ṣaḥ̄h al-Bukhārī, ed. Muhammad Zuhayr bin Nāṣir al-Nāṣir (t.tp., Dār țauq al-Najāh, 2001), 8:7 dan Muslim bin al-Hajjāj al-Naysaburī, Șahīh Muslim, ed. Muhammad Fu'ad 'Abd al-Bāqī (Bayrūt: Dār 'Ihyā' al-Turāth al-'Arabī, t.t), 4:1808

54 Hadith riwayat Bukhari, kitab adab al-Mufrad, bab faḍl al-kabīr, no. hadith 353. Lihat Muhammad bin Ismā‘̄il al-Bukhari, al-Adab al-Mufrad, (al-Riyāḍ: Maktabah al-Ma'ārif, 1998) 184. 
berupaya untuk diteliti lebih mendalam ke arah penerapannya dalam sistem pendidikan masa kini.

Para pendidik yang bertugas dalam mendidik kanak-kanak pastinya memiliki amanah dan tanggungjawab yang sangat berat untuk memastikan diri mereka selaku pendidik kanak-kanak melaksanakan amanah dan tanggungjawab tersebut dengan berlandaskan ilmu dan kaedah yang benar serta betul. Namun, berbahagialah bagi mereka yang diberikan dengan amanah dan tanggungjawab bersama kanak-kanak kerana mereka akan beroleh kebaikan yang berganda-ganda atas usaha untuk melahirkan manusia yang baik di atas muka bumi ini.

\section{Bibliografi}

Abul Hasan Muslim bin al-Hajjāj al-Naysaburī, Șahīh Muslim, ed. Muḥammad Fu'ad 'Abd al-Bāqī t.t.

Abu 'Abdullah Muīammad Bin 'Abdullah al-Ḥākim, alMustadrak 'alā al-Ṣohihain, Bayrūt: Dār al-Kutub al-'Ilmiyah, 1990.

Abu 'Abdullah Muḥammad bin Yazīd al-Qazwīn̄i, Sunan Ibn Mājah, ed. Muḥammad Fuād 'Abd al-Bāqī, t.tp: Dār 'Iḥyā' alKutub al-"Arabiyyah, t.t.

Abu 'Abdullah Aḥmad bin Hianbal, Musnad al-'Imām Aḥmad, ed. Aḥmad Muḥammad Shākir, al-Qāhirah: Dār al-Ḥadīth, 1995

Al-Sayfī, Abu Bakr bin Muḥammad. Nafāis al-Durar F̄̄ Tarjamah Syeikh al-Islam Ibn Hajar, no. 26/6, Perpustakan Universiti Malik Soud.

Al-'Aydarūs, 'Abd al-Qādir bin Shaykh. al-Nūr al-Sāfir 'an 'Akhbār al-Qarn al- 'Āṣhir. Bayrūt: Dār Șādir, 2001.

'Abd al-Mu'iz 'Abd al-Ḥamīd. Ibn Ḥajar al-Haytami. al-Qāhirah: t.p, 1981.

Ahmad Ubaedi Fathuddin, "Pemikiran Ibn Shahnun Tentang Belajar Mengajar al-Qur'an”, Forum Tarbiyah, 8, 2, ( 2010), http://takeingcareofnewborn.blogspot.com/2011/09/how-westernand-eastern-philosophers.html [23 Jun 2013]

Ibn al-'Imād, Shihāb al-Dīn 'Abd al-Hayy. Shadharāt al-Dhahab fi 'Akhbār Man Dhahab. Bayrūt: Dār Ibn Kathīr, 1986.

Ibn Manzūr Muḥammad bin Mukram, Lisān al- 'Arab, Bayrūt: Dār șadir, 1993. 
Al-Haytami, Aḥmad bin Muḥammad Ibn Ḥajar. al-Fatāwā alFiqhiyyah al-Kubrā, t.tp:Dār al-Fikr, t.t.

. Tahrir al-Maqāl fī Ādāb wa Ahkām wa Fawā'id Yahtāju Ilayha Mu'addib al-Atfāl, sunt. Muhammad Nur al-Din Marbu Banjar al-Makki, al-Qāhirah: Majlis al-Banjari li alTafaqquh fĩ al-Dīn, 1997.

International Statistic Classification of Diseases and Related Health Problems: The ICD 10 Classification of Mental and Behavioural Disorders, World Health Organization.

Lamyā' Aḥmad Abdullah Shāfi'̄̄, "Ibn Hajar Al-Makkī wa Juhūdu-Hu Fi Al-Kitābah Al-Tārīkhiyyah", Tesis kedoktoran, Universiti Umm Al-Qurā, 1996.

Al-Kandari, Lațîfah Hussin. Ta'dīb al-Tifl bi al-Lutf lā bi al- 'Unf, al-Kuwait: Wizārat al-Tarbiyah, 2011.

Muḥammad bin 'Abd al-'Azīz, Ārā' Ibn Hajar al-Haytami alI’tiqādiyyah, Riyāḍ: Maktabah Dār al-Manhaj, 2006.

Muḥammad bin Ismā'īl al-Bukharī, Șaḥ̄h al-Bukharī, t.tp: Dār Țauq al-Najāh, 2001.

Ma'ārif, 1998.

Muḥammad bin 'Īsā al-Tirmidhī, al-Jāmi'al-Kabīr, ed. Bashār 'Iwād Ma 'rūf, Bayrūt: Dār al-Gharb al-Islāmī, 1998

al-Ghazzi, Najm al-Dīn Muḥammad. al-kawākib al-Sā'irah bi 'A'yāni al-Mi'ah al-'Āshirah, Bayrūt: Dār al-Kutub al-'Ilmiah, 1997.

Muhammad Shams al-Haq Ābādi, 'Aun al-Ma'būd, t.tp: Dār alKutub al-Ilmiyah, 1995.

Al-Sarjāni, Rāghib. Qișsah al-'Ulūm al-Hậāarah al-Islamiyyah. al-Qāhirah: Mu'assasah Iqra', 2009.

Sulaimān Hussain al-Mazīn, "Qirā'ah Tarbawiyyah fi Adab alAtṭāl”, Majallah al-Jāmi'ah al-Islāmiyah, jil. 14, bil. 1, 2006.

Sulaimān bin Aḥmad al-Ṭabarān̄̄, al-Mu jam al-Kabīr, alQāhirah: Maktabah Ibn Taymiyah, 1994.

Sulaimān al-'Ash'ash al-Sijistān̄, Sunan Abi Daud, t.tp: Dār alRisālah al-'Ilmiyyah, 2009. 
Hasem, Asyraf dan Musaiyadah, Pandangan al-Haytamī Mengenai Pendidikan 